\title{
EL PENSAMIENTO EDUCATIVO DE JORGE BERGOGLIO A PARTIR DE SUS MENSAJES SOBRE EDUCACIÓN DESDE 1999 HASTA 2013
}

\section{Alfonso Martínez-Carbonell López}

\section{RESUMEN}

Con este artículo exponemos el pensamiento educativo de Jorge Bergoglio a partir de sus mensajes a las comunidades educativas en su etapa como Arzobispo de Buenos Aires desde 1999 hasta 2013. En ellos, refleja una concepción humanista de la educación y una visión optimista y esperanzadora que contrasta con el predominio de lo tecnológico y la competitividad en el actual panorama educativo y con la desmotivación y el desaliento de muchos maestros, padres y educadores. Bergoglio describe el contexto educativo y sus graves desafíos, define qué es educar y para qué se educa, traza los rasgos esenciales de todo verdadero maestro y el papel que la escuela debe jugar en el actual contexto social y educativo.

Palabras clave: Teoría de la educación, maestro, escuela, contexto educativo, desafíos educativos.

\section{TITLE: THE EDUCATIONAL THOUGHT OF JORGE BERGOGLIO FROM HIS MESSAGES ON EDUCATION FROM 1999 TO 2013}

\begin{abstract}
In this paper we present the educational thought of Jorge Bergoglio from his messages to educational communities between 1999 and 2013, when he was Archbishop of Buenos Aires. In these, he reflects a humanistic conception of education and an optimistic and encouraging vision which contrasts with the predominance of technology and competitiveness in the current educational context and with the demotivation and discouragement of many teachers, parents and educators. Bergoglio describes the educational context and its serious challenges, he defines the nature and purpose of education, outlines the essential features of a true teacher and he explains the role that schools should play in the current social and educational context.
\end{abstract}

Keywords: Theory of Education, Teacher, School, Educational Background, Educational Challenges.

Correspondencia con el autor: Alfonso Martínez-Carbonell López < alfonsomc@uch.ceu.es>. Universidad CEU Cardenal Herrera. Original recibido: 12-03-15. Original aceptado: 01-06-15. 


\section{Introducción}

Con este artículo pretendo dar a conocer el pensamiento educativo de Jorge Bergoglio, Arzobispo de Buenos Aires, a partir de sus discursos y mensajes dirigidos al mundo educativo de su ciudad desde 1999 hasta 2013, semanas antes de su elección como Papa Francisco. Pensamiento que está totalmente en consonancia con el planteamiento educativo del magisterio de la Iglesia, de modo especial a partir del Concilio Vaticano II.

Jorge Bergoglio habla no sólo como Arzobispo preocupado por la educación sino también a partir de una arraigada experiencia personal, primero como alumno y luego como profesor, que ve en la educación la clave para humanizar una sociedad postmoderna, individualista, desarraigada y sin certezas. Pide una reflexión sobre cómo educamos y una revisión sobre nuestras acciones y omisiones en el ámbito de la educación (las de todos: maestros, educadores, familias, políticos, directores de escuelas, medios de comunicación y demás agentes sociales). Su petición, le lleva a plantear preguntas fundamentales a todos los educadores y responsables educativos, ¿Para qué educamos? ¿Qué es educar? ¿Qué queremos generar?

Su pensamiento aporta al ámbito educativo una visión novedosa y esperanzadora. Él mismo, en uno de sus mensajes, describe las actitudes que se dan en el actual panorama educativo (Bergoglio, 2000). En el actual contexto, afirma, unos confían demasiado en la técnica, el progreso, los medios y los métodos como remedio para la educación. Pero él evidencia que el progreso tecnológico por sí sólo no es generador de bienestar y de crecimiento si no va acompañado de una claridad en planteamientos y objetivos de por qué y para qué educamos. En el mismo sentido, Pablo VI (1967) afirmaba que la educación básica es el primer imperativo del progreso. Por otro lado, frente a los que mantienen una actitud alarmista, excesivamente negativa, desencantada y con evidentes síntomas de cansancio, que les lleva a replegarse en sí mismos y a crear bunkers educativos ajenos a la realidad, Bergoglio, habla de esperanza, de apertura y de formar para afrontar los retos de un mundo al que hay que aspirar a cambiar. Por último, otros mantienen una actitud meramente pragmática, "hagamos lo que podamos" reduciendo la educación a una búsqueda de una excelencia aparente pero acrítica e incapaz de aportar nada para la construcción de una sociedad más humana. Frente a estas actitudes, propone una actitud de discernimiento tomando lo mejor de cada una de ellas, con esperanza y preguntándonos qué es bueno y qué es malo en la educación y hacia dónde queremos ir. 
La metodología utilizada en este paper ha consistido en tomar los discursos del anterior Arzobispo de Buenos Aires desde su primera intervención en 1999 hasta la última en 2013. Los discursos son de fácil acceso en la web del Arzobispado de Buenos Aires. A partir de ahí se ha dividido en temas coincidiendo con las ideas principales de su discurso y que han generado la estructura de este artículo. En primer lugar, analizamos la descripción que Bergoglio hace del contexto sociológico y cultural en el que se desarrolla la educación actual y los retos educativos del presente. A continuación, reflejamos su concepción personal de la educación y las claves para entenderla. Por último, exponemos las consideraciones que Bergoglio realiza sobre el papel que deben asumir en el panorama educativo actual, los maestros y educadores, la escuela, las familias y la comunidad social.

El pensamiento que aquí se refleja e interpreta, esperemos que de la forma más limpia, pura y amena posible, es el de Jorge Bergoglio, no el del autor del artículo que tratará de dar coherencia y unidad relacionando los argumentos presentes en los discursos y mensajes del anterior Arzobispo de Buenos Aires.

La clave con la que ha sido escrito este paper es la de la apertura, dando a conocer a los pensadores e investigadores en educación, las ideas que Bergoglio ofreció al ámbito educativo de su ciudad, y de Buenos Aires al mundo, mostrando su originalidad, novedad y radicalidad con las que, tal vez, valdría la pena intentar dialogar y confrontarse.

\section{Contexto de la educación en la actualidad}

Bergoglio considera que el arte de educar participa de las certezas y dificultades de la cultura que le toca vivir (Bergoglio, 2006) y a lo largo de sus discursos, homilías y mensajes describe con precisión los rasgos característicos de nuestra época y su influjo en la educación.

En primer lugar, el actual contexto es un contexto individualista en el que los vínculos sociales que han configurado la identidad de cada pueblo y nación se han debilitado dando lugar a posturas egoístas, indiferentes y aisladas. Ante esta situación, es necesario responder a través de la educación, refundando aquellos lazos sociales, creando conciencia de comunidad, de pueblo y de nación (Bergoglio, 2006) al modo como Pablo VI (197I) hablaba de la necesidad de una educación para la solidaridad como remedio frente al individualismo. 
En segundo lugar, califica el actual contexto de "estado de emergencia" ante la situación en que se encuentran parte de la niñez y la juventud. Utiliza así una expresión similar a la que Benedicto XVI (20l0) acuñó para describir el actual panorama educativo denominándolo como de "emergencia educativa". Para situarnos, hemos de considerar las dos tragedias ocurridas en Argentina a finales del 2004. Son las conocidas como tragedias de Patagones y Cromañón. La primera, ocurrida el 28 de septiembre de 2004 en un instituto de educación secundaria en la localidad de Carmen Patagones, en la provincia de Buenos Aires, se trata de la primera matanza ocurrida en una escuela en América Latina. Murieron tres jóvenes de 16 años y otros siete quedaron heridos, a causa de los disparos de un compañero de la misma edad en el aula donde se impartían las clases. La segunda fue el incendio de la discoteca conocida como Cromañón, en la que murieron 196 jóvenes, y que ocurrió el 30 de diciembre de 2004. Ambas tragedias, ocurridas en un intervalo corto de tiempo, sacudieron la opinión pública y provocaron un importante ejercicio de reflexión y debate público sobre cómo se estaba educando y cuidando a la juventud argentina. Ante estos hechos, Bergoglio pedía una revisión y discernimiento de las ideas, sentimientos, actuaciones y omisiones en la educación y se preguntaba "¿Qué pasa con nosotros que no nos podemos hacer cargo de la situación de abandono y soledad en que nuestros chicos se encuentran?" y denunciaba cómo eran sacrificados en nombre del negocio y la irresponsabilidad (Bergoglio, 2005).

En su carta por la niñez en 2005, Bergoglio describía el contexto de degradación moral en el que vivía parte de la niñez argentina, con niños explotados, abusados y abandonados $y$ ante la cual se ha respondido con un acostumbramiento progresivo $y$ una creciente pasividad e indiferencia que es síntoma de un fracaso institucional que incluye a la familia, a la comunidad y al Estado (Bergoglio, 2005).

Ante esta situación, que él denomina de tiniebla, las tinieblas de las medias verdades, de la experimentación pedagógica, del abandono, de la ausencia de cariño, diálogo y alegría, de las propuestas fáciles como la droga (Bergoglio 2009) propone llevar y abrir a los chicos a la luz. Para ello se necesita un cambio de corazón y de mentalidad que lleve a valorar y dignificar la vida de los niños.

El tercer rasgo identificativo de nuestra época es el del predominio de la técnica que ha tenido su influjo en la educación con el uso de las TIC. Del mismo modo, el magisterio conciliar y pontificio de los últimos papas, remarcaban el cariz tecnológico característico de nuestra época (Benedicto XVI, 2009). Bergoglio considera, sin embargo, que la educación no es un trabajo meramente técnico sino un trabajo 
eminentemente personal y artesanal, de alfarero. Educar es "alfarear" a los jóvenes y niños (Bergoglio, 20I2). Educar, requiere un encuentro personal entre educador y discente y no puede reducirse a una mera técnica que imposibilitaría dicho encuentro (Bergoglio, 2006).

El cuarto rasgo característico propio de nuestro tiempo es el contexto de globalización económica, de competencia mercantil, de consumo y preponderancia del mercado que afecta tanto a las familias como a los educadores. Las familias viven ahogadas y cuesta arriba la tarea de promover el desarrollo humano de sus hijos, y los educadores acometen múltiples tareas ajenas a lo meramente educativo que les agotan y les hace limitar su acción educativa a enseñar tal o cual disciplina pero poniendo en peligro el compromiso necesario. La hiperinflación del mercado, donde todo se compra y se vende, ha influido en la consideración del ser humano. De este modo, sólo es importante y se valora a quien puede consumir. Quien no consume no existe, es excluido y apartado pero quiere seguir existiendo y reclama lo suyo a los que tienen y consumen que, como respuesta, se atrincheran y se cierran. Así, la exclusión y la autorreclusión son las consecuencias del reduccionismo economicista en que vivimos (Bergoglio, 2007), en línea con Juan Pablo II (I99I) que también animaba a realizar una gran obra cultural y educativa en la sociedad meramente economicista y consumista. Bergoglio afirma que la globalización tiene dos caras, una negativa, esférica, que tiende a diluir las identidades y a uniformar y otra positiva, poliédrica, que respeta la identidad de cada uno manteniendo la identidad en la diversidad (Bergoglio, 2007).

En el año 2000, año de la profunda crisis económica que vivió Argentina, escribe un Mensaje a la comunidad educativa porteña, en la que analiza y describe la crisis y la considera como un desafío a la esperanza. Crisis que va mucho más allá de sus consecuencias económicas afectando a la concepción antropológica del ser humano y a los pilares fundamentales de la convivencia social. ¿En qué consiste dicha crisis? Es ante todo una crisis global que afecta a todos los ámbitos de la realidad (educación, política, economía, sociedad) lo que significa que es una crisis con raíces profundas. Ante esto pide revisar las claves culturales vigentes y las creencias arraigadas, los criterios que nos sirven para juzgar la realidad. $Y$ afirma, "lo que está en crisis es el modo en que la Humanidad lleva adelante su existencia en el mundo" y esto toca todas las esferas humanas, entre ellas la educación (Bergoglio, 2000). Pero es además una crisis histórica, pues es el devenir de la civilización occidental la que arrastra al planeta entero y sacude las certezas fundamentales (Bergoglio, 2000). 
Bergoglio señala las cuestiones que, a su juicio, remarcan el cambio de época en que vivimos y que influyen en la tarea educativa: Los avances tecnológicos y la sociedad del conocimiento por encima de la mano de obra; la economía mundializada y la libre circulación decapitales; la profundización de los desequilibrios internacionales queexcluye a los países pobres y a sectores enteros de la sociedad; el desempleo, como problema estructural de la economía actual, que provoca la proletarización de los trabajadores; el agravamiento del problema ecológico; el surgimiento de nuevos nacionalismos y de la xenofobia, que conlleva problemas educativos como la exclusión social, étnica y cultural; la pérdida de vigencia de los partidos políticos y la baja participación política que hace surgir otros medios de participación, ligados a reivindicaciones parciales; la revolución informática y multimediática; el fomento de la realidad virtual que afecta a la educación por sus importantes consecuencias antropológicas; la transformación del papel de la mujer; $y$, por último, la expansión de los fundamentalismos y la profusión de nuevas formas religiosas cercanas a lo místico y a lo mágico (Bergoglio, 2000).

Todo ello afecta de forma plena a la educación y plantea un reto al mundo educativo que describimos en el siguiente epígrafe.

\section{Desafíos de la educación en la actualidad}

Ante este panorama la educación se siente afectada por un lado, porque participa de los mismos problemas de la época e interpelada por otro, porque puede ser vista como clave para construir una nueva época. Exponemos a continuación cuáles son los desafíos que son necesarios asumir en el actual contexto educativo.

En primer lugar, el desafío que Jorge Bergoglio denomina "educar creando armonía entre el límite y el horizonte" (Bergoglio, 20I2). La educación tiene como finalidad lograr la armonía interior de la personalidad del joven y la armonía en la convivencia social. Educar buscando la armonía es educar al alumno o alumna para la luz y la claridad en medio de un contexto de tiniebla en el que muchos jóvenes actuales son empujados a vivir. Para responder al desafío de educar para la armonía, el educador debe acompañar personalmente al joven y realizar con él un trabajo artesanal alfareando su corazón y su vida y debe educar entre el límite y el horizonte, en una prudente tensión entre ellas. Educar en el límite es educar en el "no todo vale", y esto ayudará al joven a tener un punto de apoyo, unas referencias que le darán fundamento, solidez y profundidad. Pero tiene que coexistir con una educación para el horizonte, que le ayudará a vivir en libertad y esperanza, mirando hacia delante en 
la realización de su propio destino. La educación debe moverse equidistantemente entre estos dos polos: límite y horizonte, sin prevalecer uno sobre el otro, confiando en el alumno o alumna e incentivándole. Así es como se logra la armonía interior, se ayuda a crecer y a madurar. Educar sólo en el límite anula y apoca la personalidad, acorta la libertad y no deja crecer. Educar sólo en el horizonte, es educar en el "todo vale", sin referencias ni puntos de apoyo que termina desorientando al joven haciéndole creer que no hay límites, que todo está permitido cayendo en un relativismo existencial que al final, anula su libertad y lo esclaviza.

Un segundo reto de la educación hodierna es la de crear certezas en medio de un contexto de relativismo del que se han aprovechado otros, para hacernos creer que las únicas certezas sólidas son las propuestas de los eslóganes de consumo y la imagen. En medio de este contexto, la educación cristiana y humanista basada en una concepción trascendente de la persona, puede asumir dos actitudes. Una es la de atrincherarse, lamentarse, desconfiar, cerrarse en sus métodos, caer en la autocomplacencia y en el seguimiento de viejas recetas educativas ya experimentadas. Pero así, no se conseguirá fruto alguno. La otra opción, más positiva, busca aportar, anunciar, testimoniar y eso no se puede hacer con miradas hoscas. Para concretar y encarnar esta idea, Bergoglio propone el caso del profeta Jonás, seguro en su mundo, pero al que Dios envía a ir más allá de sí mismo, salir al encuentro de los habitantes de Nínive. Jonás adopta en un principio, la solución de huir, de seguir sus esquemas preconcebidos, atrincherarse, pero Dios se las ingenia para que cumpla con su misión y recordar a los ninivitas el amor y la misericordia de Dios. El mismo proceso debe hacer el educador, no huir, no lamentarse, salir de sí mismo y salir al encuentro de los jóvenes y niños para mostrarles la grandeza del amor de Dios. Bergoglio propone por tanto aceptar el riesgo de una nueva educación, fruto del encuentro con Dios, que nos empuja a ir más allá de lo conocido (Bergoglio, 2007).

Denominamos el tercer reto, el reto del pacto, lograr lo que tantas veces se considera imposible, un pacto educativo. Idea que también fue expresada por el Concilio Vaticano II como necesaria en el actual panorama educativo (Concilio Vaticano II, 1965). Un pacto que implique a todos y a todos los niveles: entre padres y docentes, entre personal docente y no docente, entre Estado y credos religiosos. Cuando este pacto se rompe, y cada uno tira para su lado, las víctimas irremediables son los chicos y chicas de nuestras escuelas. Se trata de lograr lo que Bergoglio denomina un "pacto de amor" que ponga a los chicos en el centro con toda su realidad y que haga que todos los agentes educativos se "manchen las manos" en la tarea 
de alfarear a los muchachos y acompañarles en su desarrollo personal (Bergoglio, 2006). Denuncia que hoy en día la educación, habla del contexto argentino pero bien se podría extender al mundo educativo en general, está dominada por un círculo de intereses ajenos a la educación misma, de modo que se olvida al chico y al joven que es el auténtico centro de la educación. Los agentes educativos (padres, alumnos, docentes, directivos, gremios o sindicatos, estados) no tienen objetivos comunes lo que provoca la dispersión y el encerramiento y la búsqueda de los propios intereses particulares. Bergoglio propone un verdadero pacto por la educación entre todos los agentes, que permita la superación del conflicto provocado por la confluencia de intereses distintos y poniendo en el centro a los alumnos y alumnas. La solución, para él, no puede consistir en la absorción o preponderancia de unos agentes sobre otros. Tampoco en un "pactismo" que busque una síntesis de las distintas posturas. La solución está en la superación del conflicto en un plano superior, que permita por el bien de los alumnos, renunciar a los propios egoísmos en una actitud de confianza mutua. Implica encuentro entre todos, diálogo y reconciliación con miras al bien común (Bergoglio, 2006).

Para salir de la espiral centrífuga del egoísmo y el individualismo, es necesario asumir un cuarto reto que Bergoglio denomina, "el desafío de formar ciudadanos solidarios con sentido colectivo de comunidad". Educar es crecer y sólo se crece en el seno de una familia y un pueblo. Es una idea igualmente tratada por los papas anteriores como Pablo VI ( 197 I) en la Octogessima Adveniens, Juan Pablo II (I 987) en la Sollecitudo Rei Socialis y Benedicto XVI (2009) en la Caritas in Veritate. En un contexto de globalización es necesario refundar, a través de la educación, los lazos sociales. Educando se construye la sociedad, y se forjan actitudes de responsabilidad hacia ella (Bergoglio, 2006). Para romper esa lógica del individualismo competitivo propio de nuestra época, Bergoglio propone asumir el desafío de educar excelentemente en solidaridad como marca de fábrica de toda educación cristiana. Ello supone crear una nueva mentalidad, una forma nueva de entender la actividad y la comunidad humana que rompa los desequilibrios e impida que se produzcan. Se trata de educar para una solidaridad excelente, más allá del sentimentalismo, que sea eficaz, profunda y renovadora que proponga fines elevados y medios adecuados (Bergoglio, 2004).

Por último, otro reto enunciado por Bergoglio es "educar para dar frutos sin descuidar la producción de resultados". Explica la distinción entre educar para el fruto y educar para los resultados. La educación para dar frutos, es una tarea persona a persona que busca provocar un cambio del alumno o alumna a partir de la asimilación 
de los nutrientes dados por el profesor que el muchacho ha incorporado a sí y ha engendrado en él una creatura nueva. En consonancia con Juan Pablo II (I98I) que señalaba que el fin principal de todo proceso educativo es construir al hombre y con Pablo VI (1967) que remarcaba igualmente la idea de la educación como necesario germen para el crecimiento del ser humano. Sin embargo educar para producir resultados, es más propio de un contexto industrial de trabajo en serie y calculable, con procesos de control, planificación y previsión. En el actual contexto educativo, en el que se busca la eficacia por encima de todo, hay una tendencia a sobrevalorar el resultado en perjuicio del fruto y lo que Bergoglio propone es conjugar frutos y resultados, buscar por encima de todo, crecimiento interior, imprimir ideales y modelos abiertos y potenciar la originalidad de cada muchacho o muchacha sin pretender crear réplicas de nosotros mismos y al mismo tiempo producir resultados y tener buenos procesos de enseñanza. Afirma, "nuestro objetivo no es educar a personas que sean útiles a la sociedad sino que puedan transformarla" (Bergoglio, 2004). Anima a despegarse en la educación de todo criterio economicista que busca invertir sólo allí donde se pueden obtener resultados. No debe haber nada más gratuito que la educación cuya eficiencia no puede medirse en términos económicos sino en términos de gratuidad. La eficiencia de la escuela está en dar gratuitamente (Bergoglio, 2008).

\section{Qué es educar, para qué se educa, cómo se educa}

Entramos en lo que consideramos el meollo del pensamiento educativo de Jorge Bergoglio, lo que él entiende por educación, cuáles son sus fines y cuáles son sus métodos.

La educación es ante todo, una actividad personal y espiritual que requiere un encuentro personal (recordemos es una labor artesanal, de alfarero). No es una actividad meramente técnica, se necesitan personas. En el hecho educativo se realizan dos encuentros. Uno, el encuentro entre educador y educando, por el que aquel acompaña a éste por el sendero interior hasta lograr el segundo encuentro que es el encuentro consigo mismo, con su "yo" más íntimo. Ese encuentro se da entre una persona que ha recorrido el camino y otra que confía en el otro para recorrerlo. Implica para que se dé, una actitud de apertura en el educador, de "éxodo", de salida de sí mismo, superando el egoísmo y la cerrazón que son impedimentos serios para que se propicie el encuentro educativo. Educar es, pues, acompañar a la persona en su proceso de madurez y desarrollo (Bergoglio, 2006). 
Esta concepción de la educación como encuentro personal tiene su base en una concepción de la persona como caminante, como "homo viator" y la vida humana como un camino. El hombre, afirma Bergoglio, es un caminante llamado a iniciar y recorrer un camino. Es un ser "vocado", llamado, no a estarse quieto sino a salir de sí mismo y caminar en la esperanza. La vida es un camino y educar es ayudar a recorrer ese camino en el encuentro hacia la verdad. El joven que se educa es un ser "inquieto", con deseos, que se abre a la vida, que inicia un camino, que busca y se pregunta y el educador no puede huir de su responsabilidad de educar esa inquietud, no puede apagar y mutilar esos deseos sino que debe saber leer la inquietud del corazón (Bergoglio, 2008).

Educar es acompañar al joven en su proceso de maduración. La madurez humana se define como la capacidad de usar nuestra libertad de modo sensato y prudente. Es algo más que madurar un fruto que depende sólo de las condiciones ambientales y de la genética. Madurar implica necesariamente dos cosas: tiempo y libertad. Necesita que el tiempo haga su labor, sin presiones, y sin forzar, respetando la velocidad de cada uno, sin aplicar la velocidad digital a todo. Madurar significa que, debe pasar un tiempo de espera entre el estímulo y la respuesta, en el que no se debe uno precipitar $y$ en el que es preciso saber esperar. Pero también la madurez implica libertad. La educación no busca la adaptación social pues se negaría así la libertad. El reto está en educar para la libertad haciendo que el joven tome posición desde sí mismo en relación con su ambiente y sus circunstancias (Bergoglio, 2005).

Este es el centro del pensamiento educativo de Bergoglio, educar es acompañar al joven en su proceso de madurez hacia el encuentro con la verdad, que es el fin último de sus deseos e inquietudes. La verdad, no se posee, se desvela, se descubre y se la encuentra hasta convertirse en certeza de la propia existencia. La verdad siempre va acompañada de la bondad y la belleza por eso el proceso educativo no consiste en transmitir meros contenidos e información sino que debe armonizarse con la propuesta de unos valores y hábitos de conducta. Educar implica trabajar armónicamente todas las potencialidades de la persona que se ponen en juego en la búsqueda de la verdad. En primer lugar, el mundo de los deseos, de la intimidad, radicados en el corazón humano, fuente de sus inquietudes y decisiones más personales y el mundo de los valores que afecta a los ojos con los que se percibe la belleza de las cosas y su dignidad, suscitando los deseos íntimos del corazón. En segundo lugar, el ámbito de la ortodoxia, de los buenos pensamientos y razonamientos que tiene que ver con la lengua y los oídos. Y, por último, el ámbito de la ortopraxis que tiene que ver con las manos y los pies, con los que el discente actúa en libertad con el fin de transformar la realidad (Bergoglio, 2008). 
La educación debe ser el modo con el que la humanidad protege y preserva a las futuras generaciones, es hacerse cargo del niño o de la niña, cuidándole, protegiéndole porque el niño sabe que si alguien se hace cargo de sus problemas y de su crecimiento, confía y está en paz. Así es como se forja la civilización de cuidarnos mutuamente (Bergoglio, 200I).

Para Bergoglio, los métodos apropiados para lograr el fruto educativo son el diálogo y el testimonio. El diálogo es lo propio entre caminantes y el educador debe ser capaz de suscitar en el educando las preguntas fundamentales para realizar ese camino. El diálogo exige cercanía, proximidad y apertura como clima y ámbito propios del encuentro educativo. Si la educación exige la armonía entre contenidos, hábitos y valores, no basta la mera explicación o la sola información sino que se necesita mostrar una síntesis vital, de modo que, el educador, de compañero de camino se convierta en testigo (Bergoglio, 2008).

Cuatro son las tentaciones de las que el educador tiene que huir. La tentación del fundamentalismo que se apropia de la verdad y la patrimonializa provocando conductas impositivas, violentas, y cerradas, que mutilan el deseo de descubrir la verdad. La tentación de la desesperanza, que suscita en los jóvenes una actitud de instalación y de quietud que hace que se refugie en el consumismo y la posesión material impidiéndole llegar al fondo de su corazón. La tentación del enciclopedismo, que confunde la verdad con "saber cosas" superficialmente y que no empuja a transformar la realidad sino sólo a ordenarla. Cree que basta con explicar contenidos y conceptos dejando a un lado los valores, la belleza y la bondad con las que transformar la realidad. Y, por último, la tentación del temor, del miedo al otro, de la xenofobia de lo diferente, de la cerrazón en sí mismo, que impide el diálogo y el salir de sí mismos como requisitos básicos y fundamentales, sin los cuales, se imposibilita el encuentro educativo y, por tanto, no hay educación.

\section{La esperanza como clave de lectura del pensamiento educativo de Jorge Bergoglio}

Los mensajes educativos del anterior Arzobispo de Buenos Aires están penetrados por un mismo hilo conductor que los unifica y que constituye la idea central de su discurso educativo. Este hilo conductor es la "esperanza" en la educación. La esperanza es una virtud esencial e intrínseca al propio proceso educativo hasta tal punto que si no se vive, el acto educativo se corrompe y se desvía de su objetivo. La educación es un acto que tiende al futuro, que recoge sus frutos en el futuro, 
que requiere, como ya hemos visto en el anterior punto, saber esperar. Si no hay esperanza, sencillamente, no se puede educar. Por eso Bergoglio, anima a todos los educadores, docentes y padres de familia a vivir esta virtud en un contexto en el que todo parece llamar al desaliento. Hay razones para tener esperanza pues los chicos necesitan esperanza. El hombre, recordemos, es un ser en camino, un caminante hacia algún lugar, un ser proyectado, llamado a salir de sí mismo y a caminar en la esperanza. Su propio deseo de búsqueda de la verdad le hace proyectarse hacia delante y sin esperanza ese deseo se adormece y se enturbia haciendo que el joven se instale y se acomode en una resignación y un conformismo que le corta las alas (Bergoglio, 2008).

La imagen del horizonte es tomada por Bergoglio para describir el acto educativo. La educación es una tensión entre pasado, presente y futuro. El punto de partida es el pasado, la tradición, lo que trabajó y forjó la anterior generación, el patrimonio cultural que antecede y que constituye el punto de partida del educando. El trabajo del don recibido es la labor del presente del educando, su asimilación, su juicio crítico y su proyección al futuro que constituye su horizonte, sus ideales, sus utopías, sus sueños. Por eso, hay que enseñar al joven a mirar con los dos ojos. Uno de carne, que le hace ver la realidad, la analiza, la asimila y la interpreta y uno de cristal, que constituye sus sueños e ideales más altos (Bergoglio, 2010).

Por eso considera que la esperanza es la dracma perdida de la educación, la moneda que se ha perdido en el contexto educativo y que hay que encontrar $y$ recuperar. La llama, la "niña esperanza", la más pequeña de las virtudes teologales pero fundamental en la educación pues educar es un acto de esperanza ya que se educa para construir un futuro y hacer una sociedad mejor. Es necesaria la esperanza para los educadores, que tienen que abandonar todo ejercicio de pesimismo pues la educación les reclama enteros (Bergoglio, 2008).

Sin duda, el peligro a batir en la educación contemporánea es el temor y el desaliento. La educación tiene como fin, el promover libertades responsables y comprometidas $y$ esto es tan grande que no cabe el temor. Es necesario quitar la piedra del temor que encierra a los jóvenes y a los docentes impidiéndoles salir de sí mismos. El docente está llamado a no temer en un contexto que nos quita las certezas y nos parece condenar a una especie de fracaso a priori (Bergoglio, 2007).

En su mensaje del año del 2000 , el año del corralito, de la profunda crisis económica y social vivida en Argentina, Bergoglio titula su mensaje educativo "Esperó contra toda esperanza". Es un año que no sólo por la crisis argentina sino por la significación 
histórica de un cambio de milenio supone un tiempo para discernir el rumbo y el sentido en un contexto en que se nubla el futuro, se borran los horizontes y surgen las angustias. $Y$ en ese tiempo marcado por la desorientación, invita a reflexionar sobre la esperanza en la educación como la cuestión más importante en ese cambio de época (Bergoglio, 2000).

En ese contexto, es necesaria la esperanza no como deseo ingenuo de un futuro mejor sino como fuerza que nos hace mirar la realidad y atender los retos de la realidad tal cual es. La esperanza es la sustancia misma del empeño de todo educador pues su tarea no consigue resultados inmediatos y sería un sinsentido si el educador no tuviera la esperanza sólida de que lo que enseña y transmite tendrá fruto a su tiempo. En un pasaje de su mensaje afirma:

"¿Qué sentido tendría consagrar las propias fuerzas a algo cuyos resultados no se ven inmediatamente, si todos esos esfuerzos no estuvieran enhebrados por el hilo invisible pero solidísimo de la esperanza? Ofrecer unos conocimientos, proponer unos valores, despertar unas posibilidades y compartir la propia fe, son tareas que sólo pueden tener un motivo: la confianza en que esas semillas se desarrollarán y producirán fruto a su tiempo y a su manera. Educar es apostar y aportar al presente y al futuro. $Y$ el futuro es regido por la esperanza”. (Bergoglio, 2000).

\section{La fisonomía del Educador. Sus retos y sus temores}

A lo largo del artículo se han reflejado muchas ideas que el anterior Arzobispo de Buenos Aires dirige a los educadores y sobre los educadores. No quisiéramos repetir ideas que ya han sido esbozadas pero creemos que no estaría completa la descripción de su pensamiento educativo sin exponer, aunque sea someramente, algunos trazos más sobre la figura del maestro y de la vocación docente que para él está revestida de enorme relevancia y grandeza y es expresión del amor social (Bergoglio, 2006).

Jorge Bergoglio denuncia la difícil situación que viven los profesores y maestros en el contexto argentino. Por eso, el tono que muchas veces adquieren sus mensajes es de aliento, motivación y reconocimiento hacia ellos. Describe la situación de desgaste en que viven, su soledad, consecuencia de un pacto educativo roto, cómo son desautorizados por los padres, superados por el exceso de trabajo, con ratios de alumnos excesivas y sueldos bajos que les llevan a tener dos trabajos. En definitiva, denuncia la falta de reconocimiento hacia la labor de los maestros que considera como una pobreza que hay que solucionar. Cambiar el rumbo de la educación supone, en primer lugar, reconocer la labor de los maestros y profesores (Bergoglio, 2010). 
El maestro debe estar revestido de unas virtudes y actitudes esenciales para educar. La importante tarea educativa que llevan a cabo les exige altura humanística y compromiso hacia sus alumnos. $Y$ es ésta la primera actitud que debe poseer un maestro: la cercanía, el compromiso, la responsabilidad paternal hacia sus alumnos porque en el actual contexto de desaliento y cansancio la tentación del educador es precisamente la de huir de su responsabilidad (Bergoglio, 2008). La tarea de educar no se inicia y termina en el aula sino que el maestro debe preocuparse por lo que hacen los alumnos fuera de la escuela, qué tipo de vida llevan, si han caído en el infierno de la droga o si viven esclavizados por el vicio. No puede convertirse la tarea educativa en cumplir el expediente, en acometer una tarea meramente funcionarial, dando a los alumnos tres o cuatro ideas que realmente no le llegan y no le sirven para nada y luego regresar a casa tan tranquilos. Considera que hay que tomarse en serio a los chicos, sacudirse el temor, el cansancio y la apatía y comprometerse con ellos, enseñándoles a soñar abriéndoles a lo que ya hemos descrito como el horizonte de la esperanza (Bergoglio, 20l0). Los educadores no deben olvidar que la educación cumple una importante función de protección hacia los más jóvenes y por eso ellos deben luchar contra ese cansancio a veces tan habitual y ser expertos en cuidar y proteger a sus alumnos ofreciéndoles un anuncio de vida y de luz (Bergoglio, 2009). Precisamente, la cercanía y la responsabilidad que todo maestro debe tener hacia sus alumnos se desprende de ser su acompañante en el camino de su realización personal, ayudándoles a orientarse en esa tensión ya descrita entre el límite y el horizonte, leyendo y ayudándole a interpretar las inquietudes de su corazón (Bergoglio, 2008). Sólo desde la cercanía, haciéndose próximo y prójimo del chico o chica se puede educar. Es necesario que el educador se ponga al alumno al hombro, se preocupe por él, lo reconozca como prójimo sin esperar beneficio alguno (Bergoglio, 2006).

Un segundo rasgo que debe caracterizar al maestro es ser testigo. El testimonio, diría Bergoglio," es lo que unge maestro al educador", debe encarnar en su propia vida lo que dice, "convirtiéndose en icono vivo de la verdad que enseña" que es lo que despierta en los chicos la sana inquietud del corazón. Pone como ejemplo a la misma persona de Jesús que enseñaba uniendo contenidos, percepciones, valoraciones, hábitos, hablando al hombre entero (Bergoglio, 2008).

Una tercera característica que debe tener todo buen educador es la apertura de corazón contraria a la actitud de cerrazón que impide el encuentro educativo y el diálogo entre docente y alumno (Bergoglio, 2006). La educación, ya lo hemos afirmado, es un diálogo y entraña necesariamente una actitud de apertura por parte 
de las dos partes. En esa dialéctica hay un encuentro entre uno que educa y otro que se deja educar. Bergoglio, para ejemplificar esta idea, se sirve del relato de la multiplicación de los panes. Como en el relato evangélico, en el acto de educar se produce el encuentro entre un joven que aporta su solidaridad, lo más grande que tiene, la inquietud de su corazón, sus cinco panes y dos peces y la soledad del maestro, y entre los dos, son capaces de saciar el hambre de ilusión y el alma de los demás y del propio joven. Para ello, es necesario dejarse interpelar por los chicos, por sus travesuras, por su solidaridad, por sus inquietudes. Si el docente no tiene un corazón abierto, si no aprende también de sus alumnos, se estanca, se enrancia y el chico o chica se queda sólo con sus cinco panes y dos peces, sin darse a los demás, con el peligro de convertirse en viejos antes de tiempo. El que está al frente del aula es un hombre o una mujer eminentemente "solos" que deben ser capaces de sobrellevar esa soledad para acoger los dones que el chico y la chica ofrecen, su solidaridad, sus cinco panes y dos peces (Bergoglio, 2007). El maestro, no sabe cuándo germinará lo que ha sembrado, ni sabe cuándo alcanzará al otro con sus acciones pero sí debe saber que cuánto más se dedica a lo pequeño, a lo ordinario y cotidiano, más enlaza su acción con lo grande, lo común, lo social, la nación y el pueblo (Bergoglio, 2006). La erosión educativa ha hecho que los educadores se conviertan en espectadores y no en protagonistas.

\section{La escuela. Templo del saber y espacio de socialización}

La principal tarea de la escuela es socializar a los muchachos, más allá incluso de transmitir conocimientos. La escuela debe crear lazos sociales entre los muchachos de modo que los motive a construir comunidad, a constituirse como pueblo, conscientes de su identidad y de tener un destino común como pueblo (Bergoglio, 2006). Es un espacio privilegiado de socialización y de relación entre generaciones y constituye el principal medio para lograr la inclusión social. Del mismo modo, el magisterio de la Iglesia siempre ha señalado la importancia de la escuela para el desarrollo intelectual, cultural y moral de los niños y niñas y como medio para su desarrollo profesional y laboral (Concilio Vaticano II, 1965). Por eso hay que poner todos los medios que sean precisos para evitar el abandono escolar pues éste, lleva a la exclusión social. Pero Bergoglio quiere dejar claro que la escuela no es un centro de asistencia social que sustituya a las familias. Su papel socializador lo cumple formando ciudadanos libres y conscientes de sus derechos. Pide no confundir el derecho a la educación con el derecho a la escolaridad pues eso vaciaría a la escuela de sentido 
(Bergoglio, 2005). Afirma que, desgraciadamente en la actualidad, muchos padres han desistido de la educación de sus hijos y han perdido protagonismo y autoridad dejando la forja interior de los chicos en manos de psicólogos y no de educadores (Bergoglio, 2006). La escuela es el medio para cambiar la sociedad donde se forjan las virtudes que la construyen: el desprendimiento, la generosidad y la primacía del bien común. No hay que permitir que la mentalidad competitiva e individualista colonice las escuelas (Bergoglio, 2003). La escuela es también el lugar de la sabiduría, un "laboratorio existencial, ético y social" donde probar las cosas que desarrollan en plenitud y construir habilidades para llevar adelante proyectos de vida. Es un espacio de preparación para el desarrollo personal de los individuos (Bergoglio, 2004).

Es también un lugar de acogida cordial que no se opone a que la escuela sea un lugar de seriedad, de eficacia y de profesionalismo. Vivimos en un mundo en el que se tiende a oponer gratuidad y eficiencia, libertad y deber, corazón y razón, y en la escuela es posible superar esta confrontación en un plano superior que es el plano de la sabiduría, que permite crear un espacio a la vez de acogida y de crecimiento. Muchos de los que acuden a la escuela lo hacen en situación de orfandad y la escuela debe tornarse familia. Por eso la familia tiene que ser un lugar de arraigo, de desarrollo de los vínculos de afecto y ternura (Bergoglio, 200 I).

La escuela debe crear lazos sociales que haga que las personas construyan comunidad y adquieran sentido de pueblo. Por eso considera a los maestros verdaderos "padres de la patria" (Bergoglio, 2003).

\section{Conclusión}

El panorama educativo actual es de "emergencia educativa". Así lo describió Benedicto XVI en su discurso a la Asamblea Diocesana de Roma, el II de junio de 2007 y desarrolló en un discurso posterior a los obispos italianos en 20 I0. En tal contexto de emergencia y de especial gravedad, Bergoglio propone un pensamiento educativo que aporta luz y propuestas concretas con las que, tal vez, enderezar el rumbo de la educación en el umbral de la postmodernidad. Pensamiento que, en total consonancia con el magisterio pontifico anterior, podemos sintetizar en seis palabras: persona, comunidad, compromiso, apertura, pacto y sobre todo, la "dracma perdida" de la educación: esperanza.

Persona, en cuanto centro y finalidad de toda labor educativa, como ya señalaron los anteriores pontífices como Pablo VI (1967), Juan Pablo II (I98I), Benedicto XVI 
(2009). Persona versus absolutismo tecnológico que prioriza los medios por encima de los fines y Persona versus economicismo, que pretende poner la educación al servicio del crecimiento económico a toda costa y del dinero y el lucro como bienes superiores. La propuesta de Bergoglio es recuperar la centralidad de la persona en la educación y dotar a ésta de un necesario fundamento antropológico. La educación, lo hemos visto, es una labor de alfarería, persona a persona, que requiere el cuidado, el cariño y la delicadeza de un artesano y cuyo fin es acompañar al chico y a la chica en su desarrollo y crecimiento interior en la búsqueda del Bien, la Verdad y la Belleza.

Comunidad. Crear comunidad es la coronación de la "buena" educación que tiende a recuperar los vínculos sociales que nos unen e identifican. Comunidad versus individualismo, aislamiento y encerramiento en sí mismo. Educar es hacer comunidad, volver a las fuentes históricas y a los valores que compartimos, caminar juntos hacia un mismo horizonte, constituirnos como pueblo, aprender a encontrarnos con el otro y acogerlo con solidaridad y afecto.

Compromiso con la suerte del chico, de la chica, de la sociedad y del país. Compromiso versus desistimiento educativo y abandono por parte de algunos educadores que terminan arrinconando a los muchachos, que desisten de su labor educativa y se niegan a "mancharse las manos". Compromiso de las familias para que, si lo han perdido, recuperen el protagonismo en la educación de sus hijos y también, compromiso de los maestros, de los directivos y de las instituciones. Compromiso versus mediocridad, que se contenta sólo con cumplir el expediente, en una búsqueda acrítica y neutral de una excelencia superficial pero que es incapaz de llegar y tocar lo hondo y profundo de los muchachos, dejándolos en la cuneta, desorientados y desmotivados.

Apertura que permita abrir las escuelas a todos, no sólo a los que piensan o sienten como yo. Apertura versus bunkerización de la educación, que tiende a construir islas educativas, ajenas a la realidad.

Pacto, que ponga en el centro a los chicos y chicas que son educados y que permita superar los intereses particulares por el bien de los alumnos, implicando a todos los agentes educativos en clave de diálogo, confianza, encuentro y reconciliación en aras del bien común. Pacto verdadero versus pactismo ineficaz o mercadeo de intereses que comercie y experimente con la educación de los muchachos y que aúne fortalezas de todos evitando que cada uno haga la batalla por su parte y muchas veces tristemente solos. 
Y por último, esperanza, la virtud por excelencia en la educación, tan necesaria y tan urgente en estos momentos. Esperanza versus desaliento y desmotivación. Una esperanza que sacuda las conciencias de los educadores, haciéndoles conscientes de su importante labor, que les ilusione y contagie ilusión a los niños y jóvenes, verdadera esperanza de todos los que hemos escogido la vocación de educar.

\section{Referencias}

Benedicto XVI (2007). Discurso. Inauguración de los trabajos de la Asamblea diocesana de Roma. Recuperado el 29/05/20I5 de <http://w2.vatican.va/content/benedict-xvi/es/ speeches/2007/june/documents/hf_ben-xvi_spe_200706 I I_convegno-roma.html > .

Benedicto XVI (2010). Discurso a la $6 I^{a}$ Asamblea General de la Conferencia Episcopal Italiana. 27 de mayo de 2010. Recuperado el 29/05/20I5 de $<$ http://w2.vatican.va/content/benedict-xvi/es/speeches/2010/may/documents/hf_ ben-xvi_spe_20100527_cei.html>.

Benedicto XVI (2009). Carta encíclica. Caritas in veritate. 29 de junio de 2009.

Bergoglio, J. (2000). Mensaje a las comunidades educativas. Esperó contra toda esperanza. Recuperado el 29/05/2015 de <http:/www.arzbaires.org.ar/inicio/ homiliasbergoglio.html>

Bergoglio, J. (2000). Homilía en la misa por la educación. Recuperado el 29/05/20I5 de < http://www.arzbaires.org.ar/inicio/homiliasbergoglio.html>.

Bergoglio, J. (200 I). Homilía en la misa por la educación. Recuperado el 29/05/20I5 de < http://www.arzbaires.org.ar/inicio/homiliasbergoglio.html>.

Bergoglio, J. (200I). Mensaje a las comunidades educativas. Recuperado el 29/05/20I5 de <http://www.arzbaires.org.ar/inicio/homiliasbergoglio.html>.

Bergoglio, J. (2003). Mensaje a las comunidades educativas. Educar es elegir la vida. Recuperado el 29/05/20I5 de <http://www.arzbaires.org.ar/inicio/ homiliasbergoglio.html>.

Bergoglio, J. (2003). Misa por la educación. Recuperado el 29/05/2015 de <http://www.arzbaires.org.ar/inicio/homiliasbergoglio.html>.

Bergoglio, J. (2004). Misa por la educación. Recuperado el 29/05/20I5 de <http://www.arzbaires.org.ar/inicio/homiliasbergoglio.html>. 
Bergoglio, J. (2004). Mensaje a las comunidades educativas. Con audacia entre todos, un país educativo. Recuperado el 29/05/20I5 de < http://www.arzbaires.org. ar/inicio/homiliasbergoglio.html > .

Bergoglio, J. (2005). Homilía en la misa por la educación. Recuperado el 29/05/20I5 de < http://www.arzbaires.org.ar/inicio/homiliasbergoglio.html > .

Bergoglio, J. (2005). Carta por la niñez en la $3 I^{a}$ Peregrinación juvenil a Luján. Recuperadoel29/05/2015 de <http://www.arzbaires.org.ar/inicio/homiliasbergoglio. html>.

Bergoglio, J. (2006). Palabras del Sr. Arzobispo de Buenos Aires en el Curso de Rectores. Recuperado el 29/05/2015 de <http://www.arzbaires.org.ar/inicio/ homiliasbergoglio.html>.

Bergoglio, J. (2006). Homilía en el I Congreso de evangelización de la cultura. Recuperadoel29/05/20I5 de <http://www.arzbaires.org.ar/inicio/homiliasbergoglio. html>.

Bergoglio, J. (2006). Mensaje a las comunidades educativas. Recuperado el 29/05/20I5 de <http://www.arzbaires.org.ar/inicio/homiliasbergoglio.html>.

Bergoglio, J. (2007). Homilía en la misa por la educación. Recuperado el 29/05/20I5 de <http://www.arzbaires.org.ar/inicio/homiliasbergoglio.html > .

Bergoglio, J. (2007). Mensaje a las comunidades educativas. Educar un compromiso compartido. Recuperado el 29/05/2015 de <http://www.arzbaires.org.ar/inicio/ homiliasbergoglio.html>.

Bergolio, J. (2008). Mensaje en la misa por la educación. Recuperado el 29/05/20I5 de < http://www.arzbaires.org.ar/inicio/homiliasbergoglio.html > .

Bergoglio, J. (2009). Homilía en la misa de la educación. Recuperado el 29/05/20I5 de < http://www.arzbaires.org.ar/inicio/homiliasbergoglio.html>.

Bergoglio, J. (2010). Homilía en la misa por la educación. Recuperado el 29/05/20I5 de < http://www.arzbaires.org.ar/inicio/homiliasbergoglio.html>.

Bergoglio, J. (20I2). Homilía en la misa por la educación. Recuperado el 29/05/20I5 de <http://www.arzbaires.org.ar/inicio/homiliasbergoglio.html>.

Concilio Vaticano II (1965). Declaración. Gravissimum Educationis. 28 de octubre de 1965. 
Juan Pablo II (198I). Encíclica. Laborem Excersens. I4 de septiembre de I98I. Juan Pablo II (199I). Encíclica. Centessimus Annus. I de mayo de I99I.

Pablo VI (1967). Encíclica. Populorum Progressio. 26 de marzo de 1967.

Pablo VI (197I). Carta Apostólica. Octogessima Adveniens. I4 de mayo de 197I. Recuperado el 29/05/2015 de <http://w2.vatican.va/content/paulvi/es/apost_letters/ documents/hf_pvi_apl_|97/05I4_octogesima-adveniens.html > . 